\title{
A frequência do ensino da música em regime articulado em Portugal: resultados de um projeto de investigação-ação no Conservatório do Vale do Sousa
}

\author{
Music learning in an articulated regime of attendance in Portugal: \\ results of an action research project at the Conservatory of Vale do Sousa
}

La frecuencia de la enseñanza de la música en régimen articulado en Portugal: resultados de un proyecto de investigación-acción en el Conservatorio do Vale do Sousa

\author{
ANTÓNIO JOSÉ PACHECO RIBEIRO 1 \\ MARIA HELENA GONÇALVES LEAL VIEIRA 1 \\ ${ }^{1}$ Universidade do Minho - Instituto de Educação/CIEC, Portugal.
}

$\diamond$

\begin{abstract}
RESUMO
Este artigo apresenta os resultados de uma pesquisa desenvolvida no Conservatório do Vale do Sousa em torno do ensino da música em regime articulado. Este trabalho pretendeu questionar o conceito de escola vocacional, testar possíveis redefinições do ensino da música em regime articulado e estudar as vantagens do reforço das articulações pedagógicas do ensino vocacional com o ensino genérico. A investigação-ação corporizou o projeto e contemplou dois grupos de trabalho: um do ensino vocacional e outro do ensino genérico. A pesquisa permitiu concluir que, no contexto em estudo, não é possível diferenciar, através dos resultados musicais, a população que frequenta a escola especializada e a escola genérica, colocando em causa o conceito de escola vocacional; o ensino da música na escola vocacional e na escola genérica encontra-se mergulhado em uma ambiguidade profunda; a pedagogia instrumental em grupo revelou-se uma metodologia eficaz. O ensino especializado da música necessita, assim, contemplar estratégias didático-pedagógicas de diversificação dos percursos de aprendizagem, introduzir tipologias musicais diversificadas e possibilitar a todas as crianças a aprendizagem de um instrumento musical.

Palavras-chave: Educação musical. Ensino vocacional. Ensino genérico. Ensino instrumental em grupo. Regime articulado.
\end{abstract}

\begin{abstract}
This article presents the results of a research developed in the Conservatory of Vale do Sousa on the teaching of music in an articulated regime of attendance. This body of work focused on questioning the concept of "vocational" school, testing possible redefinitions of teaching music in an articulated regime of attendance and studying the advantages of reinforcing a pedagogical articulation of the specialized subsystem and the general schools. The Action Research part of the project held two work groups: one was in a specialized school (called vocational school in Portugal) and the other in a general school. The research allowed us to conclude that, in the context in study, it is not possible to tell apart, based on musical results, the population that attended a specialized school and a general school, questioning thus the concept of "vocational" schools; the type of teaching in "vocational" schools and in general schools is deep in ambiguity; the instrumental pedagogy in a group proved to be an effective method. The specialized teaching of music needs, therefore, to contemplate pedagogical and didactical strategies that allow for diversity in learning approaches, to introduce multiple music genres and to make possible for all children to learn a music instrument.

Keywords: Musical education. Vocational schools. General education. Instrumental group teaching. Articulated regime of attendance.

\section{RESUMEN}

Este artículo presenta los resultados de una pesquisa llevada a cabo en el Conservatorio do Vale do Sousa en torno de la enseñanza de la música en régimen articulado. Este proyecto ha pretendido cuestionar el concepto de escuela vocacional, testar posibles redefiniciones de la enseñanza de la música en régimen articulado y estudiar las ventajas del refuerzo de las articulaciones pedagógicas de la enseñanza vocacional con la enseñanza general. La InvestigaciónAcción ha corporeizado el proyecto y ha contemplado dos grupos de trabajo: uno de enseñanza vocacional y otro de enseñanza general. La pesquisa ha permitido concluir que, en el contexto en estudio, no es posible diferenciar, a
\end{abstract}


través de los resultados musicales, la población que frecuenta la escuela especializada y la escuela general, poniendo en causa el concepto de escuela vocacional; la enseñanza de la música en la escuela vocacional y en la escuela general se encuentra sumergida en una ambigüedad profunda; la pedagogía instrumental en grupo se ha revelado una metodología eficaz. La enseñanza especializada de la música necesita, así, de contemplar estrategias pedagógicodidácticas de diversificación de los recorridos de aprendizaje, introducir múltiples tipologías musicales y posibilitar a todos los niños el aprendizaje de un instrumento musical.

Palabras clave: Educación musical. Enseñanza vocacional. Enseñanza general. Enseñanza instrumental en grupo. Régimen articulado.

\section{INTRODUÇÃO}

O ensino da música em Portugal processa-se em diferentes contextos, assim definidos na legislação: o ensino genérico, que se destina a todos os cidadãos, independentemente das suas aptidões e talentos específicos; o ensino especializado dos conservatórios e academias, que se destina a indivíduos com comprovadas aptidões e talentos específicos em alguma área artística; e o ensino profissional, que se destina à formação de músicos profissionais (Decreto-Lei no 344/90, de 2 de novembro).

A reforma estrutural de 1983 levada a cabo pelo Decreto-Lei no 310, de 1 de julho, foi muito importante para o ensino da música (RIBEIRO; VIEIRA, 2016a), uma vez que inseriu as artes no sistema geral de ensino e criou o conceito de escola vocacional, permitindo a frequência do ensino da música em regime articulado e em regime integrado. Não obstante a importância da referida reforma, o ensino da música em Portugal continuou a viver com dificuldades e constrangimentos. Segundo Vasconcelos (2003, p. 14) “(...) o ensino da música em Portugal nas últimas duas décadas caracterizou-se por um conjunto alargado de complexidades e de dificuldades na construção, implementação e regulação de políticas para este subsistema de ensino". Estas dificuldades consubstanciaram-se na implementação dos projetos educativos das escolas vocacionais:

(...) a ausência de uma política para o desenvolvimento da educação artística, especialmente no que se refere à articulação entre o ensino regular, o ensino especializado e o ensino profissional artístico, tem colocado constrangimentos à construção de projectos educativos de escolas, capazes de assumir as respectivas especificidades e singularidades e de mobilizar a comunidade (MINISTÉRIO DA EDUCAÇÃO, 2003, p. 2).

As dificuldades atrás referidas continuam atuais, pese embora em 2009 (Portaria no 691/2009, de 25 de junho) ter sido levada a cabo uma reestruturação do ensino artístico especializado da música que, de certa forma, veio trazer resultados positivos para este subsistema de ensino (RIBEIRO; VIEIRA, 2016b). Na realidade, a reestruturação em questão apelava para a necessidade de diversificar a oferta formativa e de criar condições de articulação entre as escolas especializadas do ensino artístico da música e as escolas do ensino genérico, favorecendo, claramente, ambientes de aprendizagem mais integrados. Efetivamente, a reestruturação mencionada colocava a tónica, inequivocamente, em ambientes de aprendizagem integradores capazes de promoverem uma maior acessibilidade ao sistema do ensino artístico especializado da música: “(...) A orientação para um regime de frequência mais integrado, ainda que em resultado da articulação entre dois estabelecimentos de ensino, é, por isso, uma condição fundamental de promoção de qualidade" (FERNANDES; Ó; FERREIRA, 2007, p. 7).

O regime articulado é um regime de frequência que permite aos alunos frequentar as disciplinas de formação geral na escola genérica e as disciplinas da área vocacional na escola de música especializada. Se desenvolveu a partir da reforma de 1983 e que veio, como o próprio nome indica, possibilitar uma articulação entre esses diferentes contextos educativos do ensino da música em Portugal. O regime integrado é um regime de frequência que permite aos alunos frequentar no mesmo estabelecimento de ensino todo o plano curricular: as disciplinas de formação geral e as disciplinas da formação vocacional. No sentido de estudar as potencialidades do regime de frequência articulado (quer do ponto de vista pedagógico, quer do ponto de vista do seu impacto na própria organização do sistema de ensino) foi desenvolvida uma investigação doutoral (RIBEIRO, 2013), cujo âmbito, objetivos e conclusões agora apresentamos.

\section{DEFINIÇÃO DO TEMA DE INVESTIGAÇÃO, OBJETIVOS E METODOLOGIA}

A problemática vivida pelas escolas especializadas de música, desde a reforma de 1983 (Decreto-Lei no 310, de 1 de julho), prolongou-se até à atualidade e proporcionou a efetivação do presente estudo levado a cabo em uma escola especializada (Conservatório do Vale do 
Sousa - Lousada - Portugal), e em uma escola genérica (Agrupamento de Escolas Dr. Manuel Pinto de Vasconcelos - Freamunde - Portugal), e concluído em 2013. Neste sentido, pretendeu-se: a) questionar o conceito de escola vocacional de música, segundo a designação legislativa; b) estudar estratégias de flexibilização e diversificação dos percursos de aprendizagem, através da possível redefinição do modelo de ensino articulado; c) investigar formas de articulação curricular e ações de cooperação concretas com o ensino genérico, com o intuito de contribuir para a construção do projeto educativo da escola. Desta forma estabeleceram-se os seguintes objetivos gerais, que se situam ao nível da pedagogia e da política educativa: a) contribuir para uma maior consciencialização da importância das relações de articulação curriculares e de ações de cooperação concretas entre escola do ensino artístico da música e escola do ensino genérico; b) promover políticas para o desenvolvimento de uma educação artística, especialmente no que concerne às articulações entre ensino artístico especializado da música e ensino genérico, de forma a reforçar a autonomia das escolas envolvidas e consolidar o seus projetos educativos; c) contribuir para uma flexibilização e diversificação dos percursos formativos, através da redefinição do ensino da música em regime articulado introduzindo novos conceitos e práticas pedagógicas do ensino de instrumento e valorizando o papel da etnomusicologia e do nosso património musical identitário. No âmbito de objetivos específicos este estudo centrou-se nos seguintes aspetos: a) desenvolver a literacia musical no ensino básico; b) constatar semelhanças, diferenças, perspectivas e motivações entre o tipo de população escolar que frequenta o ensino vocacional e o ensino genérico; c) averiguar a possibilidade de novas práticas pedagógicas do ensino do instrumento em ambos os ramos de ensino.

O trabalho empírico foi efetuado junto a dois grupos de alunos diferenciados, que frequentaram o $2^{2}$ ciclo do ensino básico: um do ensino vocacional e outro do ensino genérico. Cada um dos grupos era constituído por 4 elementos (10 anos de idade, do $1^{\circ} \underline{Q}$ grau correspondente ao $5^{\mathrm{o}}$ ano de escolaridade), dois do sexo masculino e dois do sexo feminino. Envolveu atividades estruturadas em sala de aula no âmbito do processo de ensino e aprendizagem de um instrumento musical (guitarra), tradicionalmente associado ao ensino especializado da música. Salientamos que, as aulas ministradas aos alunos do ensino especializado foram enquadradas no tempo letivo do regime articulado e as dos alunos do ensino genérico foram ministradas, a título experimental, e com as devidas autorizações, em tempo extraletivo.

A metodologia de investigação utilizada centrou-se na investigação-ação e os instrumentos de recolha de dados foram os seguintes: tabelas de observação participante, fichas síntese dos sujeitos (questionários aplicados aos alunos no final das aulas), registos em áudio e vídeo, pesquisas por questionário, entrevistas semiestruturada e concerto final. Os participantes do estudo foram os grupos de alunos selecionados, os professores do Conservatório do Vale do Sousa, os pais e os encarregados da educação dos alunos e os diretores pedagógicos das escolas envolvidas. Por questões éticas os alunos foram identificados por meio de um código: Aluno A, Aluno, B, Aluno C, Aluno D, Aluno E, Aluno F, Aluno G, Aluno H e Aluno $\mathrm{I}^{1}$.

A análise dos dados caracterizou-se por uma leitura descritiva e interpretativa minuciosa possibilitada pelos diferentes métodos de recolha e ancorada, sobretudo, no paradigma qualitativo, permitindo a interpretação e a obtenção dos resultados finais.

\section{RESULTADOS}

\section{a) Conceito de vocação e escola vocacional: ensino vocacional/ensino genérico}

De acordo com a revisão da literatura, o ensino vocacional da música ministra-se nas academias de música e conservatórios e segue os parâmetros importados dos conservatórios de raiz quinhentista que surgiram na Itália. $\mathrm{O}$ conceito de vocação inerente à formação original deste tipo de escola assentava em um carácter de cultivo e construção e apresentava uma aparência de caridade que pretendia viabilizar oportunidades para jovens socialmente desfavorecidos e integrá-los em um contexto social efetivo e profissional. De certa forma, esta raiz sóciocaritativa teve impactos muito notórios na instituição conservatório ao longo dos séculos (VIEIRA, 2009).

Em 1983, através da reforma operada pelo DecretoLei $\mathrm{n}$ o 310 , de 1 de julho, o ensino da música nos conservatórios e academias passou a designar-se de vocacional, alegando a necessidade de uma vocação precoce (artigo $1^{\circ}, \mathrm{n}^{\mathrm{o}}$ 2, p. 2389), e foi inserido no sistema geral de ensino. Esta transformação no subsistema de ensino causou inúmeros constrangimentos às escolas de música e, consequentemente, às escolas genéricas, pois ambos os tipos de escola viviam nos seus mundos, distantes uns dos outros e, até, subvalorizando mutuamente o trabalho. A reforma fazia depender as escolas de música e as escolas genéricas umas das outras, em uma perspectiva dialética que causou desafios de comunicação e que,

\footnotetext{
1 No decorrer da investigação um aluno abandonou o projeto (Aluno E) sendo substituído pelo Aluno I; um outro aluno (Aluno F) desistiu numa fase avançada do processo inviabilizando a sua substituição.
} 
verdadeiramente, não se concretizou durante décadas (regimes articulado/integrado de frequência). De fato, as relações de articulação com as escolas do ensino genérico foram sempre apáticas e feitas de costas voltadas e de grandes resistências até os nossos dias.

As transformações socioeconômicas e culturais ocorridas em Portugal, a democratização do ensino e $o$ aumento da escolaridade obrigatória, originaram o aparecimento de novas escolas vocacionais de música no âmbito do ensino particular e cooperativo, especialmente, na década de 1990 do século passado, e “(...) conduziram a uma transformação significativa no que se refere à procura do ensino especializado da música, com consequente alteração da população que passou a [frequentá-lo]" (FOLHADELA; VASCONCELOS; PALMA, 1998, p. 7). Essas escolas são, hoje, procuradas por um número elevado de crianças e jovens que procuram saberes e conhecimentos diversos que não encontram na escola genérica (pública), que não satisfaz as reais necessidades da atualidade, sempre em constante mudança. A sociedade do conhecimento implica um nível artístico capaz de acompanhar as transformações sociais, culturais e estéticas sem preconceitos e com capacidade de responder às exigências do mundo moderno. A diferente procura não foi acompanhada pela necessária introdução de ofertas curriculares diversificadas capazes de responderem às novas expectativas e solicitações da população escolar. A escola de música vê-se, assim, invadida por um número elevado de alunos que têm diferentes propósitos, que não o da escola de música no sentido tradicional, e essas escolas continuam em uma linha de ação passadista, incapazes de sustentarem um projeto devidamente habilitado, enquadrado e reconhecido no seu meio social, suscitando intervenções da comunidade e dos diferentes atores, demonstrando alguma falta de ambição curricular e de certa comodidade instalada. Sendo assim, a escola de música especializada coabita com os interesses genéricos sem, no entanto, assumir essa generalidade de metas e intenções, mas é dessa generalidade que resulta a construção da vocação quer dos desfavorecidos, quer dos favorecidos, quer dos que se consideram vocacionados, quer dos que nunca pensaram nisso; ou seja, daqueles que devem, efetivamente, frequentar a escola de música: todos.

\section{- Perspectiva dos docentes do Conservatório do Vale do Sousa sobre o ensino vocacional/ ensino genérico}

O sistema de ensino da música, ramificado em ensino vocacional/ensino genérico encontra-se, assim, mergulhado em um ambiente profundamente ambíguo sem se saber, exatamente, onde começa um e acaba o outro, e porquê. As opiniões dos intervenientes no estudo demonstram, precisamente, esta polêmica e justificam as reflexões produzidas no sentido de clarificar identidades e populações, não sendo, porém, capazes de responder sem limitações à problemática. Neste sentido, os docentes do Conservatório do Vale do Sousa entendem, como primeira conclusão do estudo, que o atual conceito de escola vocacional de música está desenquadrado da realidade nacional no que diz respeito à oferta formativa e respectiva procura. $\mathrm{O}$ ensino ministrado nas escolas de música deve ter como missão primordial a preparação de alunos para prosseguimento de estudos musicais visando à formação de futuros profissionais. Não obstante esta missão principal, a escola de música tem cumprido funções colaterais, e está envolta em funções genéricas, absolutamente incontornáveis no contexto da oferta atual.

A questão fundamental da opção vocacional poderia ser uma espécie de porta de saída para a resolução da situação pendente. No entanto, esta opção vocacional não resolve o problema, na medida em que não existe consenso quanto ao ciclo mais indicado para fazê-la: para uns o $3^{\mathrm{o}}$ ciclo seria o momento certo, para outros a entrada no ensino secundário constituiria o momento oportuno. Pese embora esta dicotomia, a problemática mantém-se porque, independentemente do ciclo da opção vocacional, esta opção não constitui a passagem da escola genérica para a vocacional para 50\% dos docentes. Para estes a opção vocacional definitiva significa, apenas, o reiterar da opção e da continuidade na escola vocacional porque, efetivamente, o trabalho já se desenvolve na escola especializada. As restantes áreas do conhecimento implicam uma escolha (opção vocacional) à entrada do ensino secundário, entendida como o abandono da formação geral, a favor de uma determinada área do conhecimento com competências específicas a considerar. Constatando os dados expostos, para metade dos docentes do Conservatório do Vale do Sousa, o ensino especializado da música necessita de uma escola específica desde o início ao fim do processo de ensino e aprendizagem, destacando-se das restantes áreas do saber pelo fato dessas se desenvolverem em escolas genéricas até à respectiva opção vocacional. Nesta perspectiva, a área específica da música assume um carácter distinto (importante) das restantes áreas do saber que, legitimamente, pode ser questionado. Se, efetivamente, a escola de música tem como função preparar os alunos para prosseguimento de estudos musicais, então os alunos que não pretendem seguir os estudos musicais não deveriam frequentar a escola dita vocacional de música, isto é, a escola especializada. No entanto, tal consideração não corresponde à verdade porque a escola vocacional de música também cumpre funções genéricas, embora desenquadradas do seu conceito e do seu espírito, por um 
lado, e por outro lado, a frequência do ensino vocacional da música não tem sido exclusiva, no Conservatório do Vale do Sousa, dos indivíduos que demonstram possuir aptidões específicas na área da música. Pelo contrário, os alunos que revelem menos aptidão musical e falta de potencial têm, de igual modo, frequentado a escola vocacional de música. Neste âmbito, no Conservatório do Vale do Sousa, todos os alunos têm frequentado o ensino da música na escola especializada, independentemente da opção vocacional futura. Ora, tal situação remete-nos para a similaridade com as restantes áreas do saber e estas se desenvolvem, até à opção vocacional, em escolas generalistas; a opção vocacional confere a passagem da escola genérica para a escola específica da área do conhecimento em questão. A este propósito, refere-se o questionamento de Vieira (2014) sobre o significado de ensino especializado da música, raízes históricas do conceito, ambiguidades e consequências na organização do sistema de ensino da música, com referência particular à noção de especialização em idade posterior dos alunos e nunca na iniciação e primeiros ciclos de estudo.

No âmbito da música, a situação é complexa e ambígua, porque, assim sendo, a frequência do ensino da música na escola vocacional (Conservatório do Vale do Sousa) tem sido generalizada ao acesso de todos os indivíduos, mas nunca assume esta designação (genérica) e, pese embora a necessidade de fazer a opção vocacional em algum momento do processo, esta manifestação não confere a passagem à escola vocacional, porque já se desenvolve na escola especializada. Neste sentido, com um acesso de mais larga escala, a escola dita genérica desapareceria do sistema porque a escola vocacional de música absorveria a totalidade dos alunos.

A escola de música, atualmente, é frequentada por crianças e jovens de diferentes estratos sociais e cujos objetivos iniciais estão longe de passar pela opção vocacional aos 10 anos de idade (frequentam a escola de música sem intenções de seguir música). As preocupações principais centram-se em uma formação geral equilibrada que permita a respectiva escolha vocacional devidamente sustentada. Assim sendo, a vocação não é (nem pode ser) um requisito a priori, mas uma aquisição conseguida a posteriori. A democratização do ensino da música tem contribuído para a aproximação e diluição entre os ramos vocacional e genérico, no entanto, as diferenças entre os ramos têm sido consideradas, pelos docentes do Conservatório do Vale do Sousa, justificativas para a existência dos mesmos. Apesar de estas diferenças fazerem sentido, fica a dúvida, depois do exposto, sobre quem deve, afinal, frequentar o ensino genérico e quem deve, efetivamente, frequentar o ensino vocacional da música.

\section{- Trabalho empírico com os grupos de alunos do Conservatório do Vale do Sousa e com o grupo de alunos do ensino genérico}

O trabalho empírico desenvolvido ao longo dos dois anos do estudo veio questionar o conceito de vocação instituído nas orientações legislativas. Os dados obtidos através do registo em áudio e vídeo, das fichas síntese dos sujeitos, do concerto final e das tabelas de observação, que visavam avaliar os resultados musicais, discriminar as motivações e expectativas dos alunos envolvidos, assim como identificar identidades musicais, concorrem para as seguintes ideias síntese:

(i) No que concerne à avaliação final dos grupos envolvidos, o nível foi bastante positivo tanto para os alunos do ensino vocacional, como para os alunos do ensino genérico. As dificuldades/ facilidades e respectivas atitudes dos grupos foram as mesmas; os problemas de uns confundiram-se com os dos outros e ambos os grupos manifestaram falta de estudo;

(ii) Relativamente ao tipo de música que ouvem em casa, os alunos do ensino vocacional da música preferem exclusivamente o pop/rock; curiosamente, os alunos do ensino genérico ouvem pop/rock, música clássica e música popular/tradicional;

(iii) No que diz respeito ao interesse profissional no âmbito da música, dois alunos do ensino vocacional manifestaram a intenção de seguir música, enquanto que, dos alunos do ensino genérico, um respondeu positivamente, outro negativamente e outro aluno, que demonstrou mais interesse, respondeu: " $\mathrm{Eu}$ tencionava, quando era pequeno, ser médico, mas agora já não sei" (Aluno I) ${ }^{2}$.

Apesar das dificuldades enfrentadas pelos alunos do ensino genérico, entre as quais a elaboração de horários e o fato do trabalho desenvolvido não fazer parte do seu currículo escolar, (lembrando que as aulas ministradas aos alunos do ensino especializado foram enquadradas no tempo letivo formal e as dos alunos do ensino genérico foram ministradas a título experimental e com as devidas autorizações, em tempo extraletivo), os resultados obtidos apontam para uma semelhança entre os dois grupos de trabalho, a ponto de não ser possível, através das audições de áudio e vídeo e dos resultados da avaliação, discriminar quais os alunos que são do ensino vocacional e quais os alunos que são do ensino genérico; os desempenhos, as motivações e perspectivas e expectativas futuras não são diferentes nos dois ramos de ensino,

\footnotetext{
2 Comunicação recebida via Ficha Síntese do Concerto Final (FSCF) no dia 24 de junho de 2010.
} 
dificultando a identidade de cada um, e todos os alunos obtiveram aproveitamento no final do $2^{\mathrm{o}}$ grau do ensino da música: a população escolar encontra-se dividida em dois ramos mas, pelo menos no caso em estudo, os resultados não.

A concessão da escola de música enquanto vocacional, apenas dirigida a quem possui vocação, talento, dom, jeito, algo de inato e de qualidade natural, é um pressuposto questionável e persistente no nosso quotidiano educativo e cultural. De fato, vocacional pressupõe a capacidade do sistema fazer a distinção entre quem tem vocação e quem não a tem. Ora, esta ideia tem se manifestado tão duvidosa, quanto complexa. Este preconceito, que só existe em relação à disciplina de música e a mais nenhuma outra, só será ultrapassado quando, efetivamente, todos os indivíduos tiverem acesso ao ensino da música (PALHEIROS, 1993) e à aprendizagem de um instrumento e puderem realizar a sua opção vocacional de forma natural e construída ao longo do percurso da vida (VIEIRA, 2008). Assim sendo, a escola vocacional de música tem um caminho a percorrer, no sentido de modificar as suas metas e estratégias de ensino, adaptando-se às necessidades das populações que a procuram e reequacionando o sentido de vocação à luz das práticas atuais. Para a consecução desses propósitos o regime de frequência articulado terá, sem dúvida, uma palavra muito forte a dizer, como se verificou neste projeto de investigação.

\section{b) Flexibilização e diversificação dos percursos de aprendizagem através da redefinição do modelo de ensino articulado}

Já foi referido, anteriormente, que o atual conceito de escola vocacional de música se encontra desfasado da realidade e que o ensino vocacional manifesta dificuldades de inserção nos seus meios sociais e culturais, apresentando-se desenquadrado e não sendo capaz de responder às presentes solicitações. $\mathrm{O}$ modelo único de currículo vigente precisa de ser substituído por modelos personalizados de acordo com as diferentes perspectivas, expectativas e motivações da população que procura as escolas. A missão principal da escola de música está assim comprometida enquanto não for capaz de encontrar soluções curriculares que permitam escolhas conscientes que possibilitem desempenhos concretos e efetivos com propósitos claros e distintos. A frequência deste tipo de ensino reclama a abolição do conceito de talento (Decreto-Lei no 344/90, de 2 de novembro), por vários motivos: os alunos inscritos não têm sido selecionados com base em talentos ou aptidões; os conceitos de talento e aptidão musical não estão suficientemente estudados; é questionável que se devam excluir alunos de um tipo de aprendizagem com base em supostos talentos (processo que não ocorre noutras áreas do saber, para as quais é dado acesso a toda a população); é questionável o conceito de ensino especializado (e ainda mais o conceito de ensino vocacional) nas idades iniciais (VIEIRA, 2014). Ora, tal ambição só será possível e efetiva no contexto atual com uma escola de música plural, renovada e com percursos formativos alternativos e heterogéneos, capazes de responderem às diferentes solicitações. A flexibilização dos percursos de aprendizagem adquire, desta feita, contornos imprescindíveis e obrigatórios na concretização da transformação do sentido de escola de música, pois a generalização do ensino da música a todos os indivíduos implica, obrigatoriamente, respostas diferenciadas sustentadas em práticas e modelos pedagógicos flexíveis para sua exequibilidade e sucesso. $\mathrm{O}$ ensino musical ancorado nas perspectivas de séculos passados não responde aos pressupostos educativos e formativos associados às múltiplas linguagens musicais $\mathrm{e}$ propostas estéticas contemporâneas; é urgente a mudança. O ensino da música precisa, assim, assumir esta realidade e as escolas necessitam fomentar seus projetos nas suas comunidades sem preconceitos de integrar nos currículos outras tipologias musicais.

Nesta pesquisa os professores do Conservatório do Vale do Sousa manifestam compreensão desta realidade complexa atual e da necessidade de democratização e entendem que a oferta formativa da escola se destina a todos os indivíduos (independentemente da opção vocacional futura e das suas supostas aptidões ou talentos na área da música). Entendem, ainda, que a sua população escolar se enquadra no espírito das escolas vocacionais, não se manifestando, no entanto, especialmente dotada ou com talentos específicos para a música; a população escolar do Conservatório do Vale do Sousa não responde na sua maioria positivamente à principal finalidade da escola de música vocacional. A população escolar do Conservatório do Vale do Sousa reclama, assim, uma nova escola de música onde a característica essencial não seja, exclusivamente, a de prosseguimento de estudos musicais, mas cujo leque de saídas proporcione também outras possibilidades educativas e musicais. Por conseguinte, outras soluções curriculares se impõem que viabilizem tipologias musicais diferenciadas, mais próximas da identidade das regiões e dos alunos que frequentam as escolas, capazes de ilustrarem os interesses e manifestações artísticas e estéticas de forma plural e sem ambiguidades nem preconceitos preestabelecidos.

O ensino da música no ensino genérico, por outro lado, encerra-se em um modelo fechado manifestamente insuficiente e a sua alteração, fundamentada na abertura a novas tipologias musicais e à aprendizagem de instrumentos (incluindo os tradicionais portugueses), 
traria vantagens para todos. Neste sentido, os protocolos curriculares com o ensino artístico especializado da música poderiam viabilizar, na escola genérica, duas vertentes de ensino: uma facultativa e outra de carácter oficial no âmbito do ensino especializado que responderiam às diferentes solicitações da população.

Os pais e encarregados de educação partilham de ideia similar, pois na sua perspectiva, a oferta formativa do Conservatório do Vale do Sousa e o ensino da música em regime articulado deveriam contemplar outras tipologias musicais, nomeadamente, a música popular/ tradicional portuguesa e a escola do ensino genérico deveria possibilitar a aprendizagem de um instrumento musical. Assim sendo, a oferta formativa do conservatório e a redefinição do regime de ensino articulado assumem particular relevância, na medida em que a frequência do ensino vocacional da música não se destina apenas aos alunos com intenções de prosseguimento de estudo; é necessário, portanto, outros modelos e estratégias de ensino que possibilitem o acesso de todos ao ensino da música e à aprendizagem de instrumentos musicais.

Os alunos do Conservatório do Vale do Sousa em regime articulado possuem a consciência do tipo de escola e do seu referencial: prosseguimento de estudos musicais na área da música. No entanto, a procura do ensino da música neste regime de frequência: articulado, situa-se, também, no âmbito do gosto pela música, pela aprendizagem de um instrumento e pela possibilidade de uma formação geral mais completa, independentemente da opção vocacional futura e do futuro profissional (apenas dois alunos manifestaram interesses profissionais no âmbito da música). Os alunos do ensino genérico manifestaram as mesmas motivações e expectativas e, a possibilidade de desempenhar funções profissionais no âmbito da música, foi equacionada por uma aluna; a motivação inicial de um aluno para ser médico foi abalada depois da experiência musical proporcionada pelo projeto de investigação, abrindo lugar à ideia da construção da vocação e à necessidade de diversificar os percursos e as práticas de forma a não excluir ninguém e potenciar o desenvolvimento de aptidões musicais.

A falta de abertura das escolas a diferentes tipologias e gêneros musicais é acompanhada também pela incapacidade do sistema em adotar soluções, mesmo que temporárias, no sentido de dar resposta à procura de um ensino musical de qualidade, por parte de uma população que não tem conseguido encontrá-la, de forma consistente em todo o País, nos estabelecimentos de ensino denominados genéricos. Assim, a tentativa de ligação da escola pública genérica à escola pública especializada emerge como uma estratégia curricular lógica e consequente, manifestando, porém, uma eventual falta de visão mais aprofundada dos objetivos gerais do sistema de ensino da música como um todo. De acordo com Silva (2000, p. 63),

[é] consensual o diagnóstico de que um problema básico do ensino vocacional da música (...) é a convergência de duas procuras distintas: uma procura que pretende, apenas ou sobretudo, uma mais valia pessoal, em termos de formação musical; e uma procura que se orienta pela aspiração a uma formação musical propriamente vocacional, para futura profissionalização.

De fato, o regime de frequência articulado promoveu a frequência dos estabelecimentos de ensino especializados por parte de, pelo menos, dois grupos de alunos: o daqueles que buscam, efetivamente, um ensino especializado e, o daqueles que apenas procuram o ensino musical que não conseguem encontrar no ramo de ensino genérico.

\section{- Práticas pedagógicas: o ensino instrumental em grupo}

Ao longo do trabalho o ensino instrumental em grupo e o reportório de raiz tradicional emergiram como forma de resposta às solicitações dos intervenientes, na sequência da reformulação dos ciclos da investigaçãoação. Não obstante o ensino instrumental em grupo andar afastado da escola de música portuguesa, quer seja da especializada quer seja da escola do ensino genérico (a Portaria no 691/2009, de 25 de junho, introduz este conceito na escola vocacional de música e em um formato de minigrupo), a sua pertinência justifica-se pela necessidade de renovação da escola e das práticas pedagógicas - apesar de ser possível supor que a referida portaria tenha sido publicada com base em preocupações de caráter econômico ou financeiro, refletidas na possibilidade de contratação de menos professores para o mesmo número de alunos. Por outro lado, reconhece-se que essas metodologias de ensino em grupo, um pouco por todo o mundo, têm ocupado um lugar visível e obtido resultados positivos.

\section{- Perspectiva dos docentes do Conservatório do Vale do Sousa sobre o ensino instrumental em grupo}

Os docentes do Conservatório do Vale do Sousa entendem que as alterações operadas pelo documento legislativo supramencionado vieram beneficiar o ensino vocacional da música em regime articulado pelo fato de permitirem um maior contato com o instrumento (número de aulas) e possibilitarem a adoção de estratégias e práticas pedagógicas diferenciadas com base na interação, motivação, vivência musical e experiências diversas. $\mathrm{O}$ ensino instrumental em grupo revela-se, assim, uma ferramenta eficaz para o processo de ensino e 
aprendizagem na escola de música especializada e, apesar de não ter passado histórico nem no ensino vocacional nem no ensino genérico (à exceção dos tradicionais grupos Orff ou de música de câmara), tal metodologia de ensino deveria, segundo os resultados desta pesquisa, fazer parte da escola de música vocacional e não deve ser exclusiva do ensino genérico.

Neste projeto o ensino instrumental em grupo não criou uma motivação acrescida para a docência, no entanto, também não criou qualquer tipo de desmotivação. No que concerne à motivação dos alunos, os resultados não são tão lineares: há uma maioria que considera que os alunos não se beneficiaram de uma maior motivação (58\%); e há um grupo que considera que os alunos mostraram uma maior motivação pelas aulas instrumentais em grupo (28\%). Apesar desta discrepância percepcionada pelos professores, dois aspectos fundamentais devem ser retidos:

(i) Os alunos não revelam um menor gosto pelas aulas instrumentais;

(ii) as aulas instrumentais em grupo obrigam os alunos a um trabalho aprofundado e, consequentemente, potenciam melhores resultados finais.

As práticas pedagógicas subjacentes ao ensino instrumental em grupo são diferentes das práticas pedagógicas das aulas individuais, porque é necessário considerar a especificidade do grupo de trabalho e atender ao seu contexto. Ensinar um grupo a tocar um instrumento não é a mesma coisa que ensinar um indivíduo a tocar esse instrumento e, assim, quem sabe ensinar um instrumento não sabe necessariamente ensinar um grupo a tocar esse instrumento. Neste contexto, impõe-se como incontornável a formação específica no curso de formação de professores no âmbito da metodologia do ensino instrumental em grupo.

O ensino instrumental em grupo pode ser fomentado em contextos diversos, no entanto, a disciplina de Instrumento do ensino vocacional foi a que reuniu um sentido prioritário. Outros contextos mencionados apontam para: (i) a disciplina de Classes de Conjunto do ensino vocacional; (ii) a disciplina de Educação Musical do ensino genérico; (iii) a disciplina de Formação Musical do ensino vocacional; (iv) uma disciplina própria a criar no âmbito do ensino vocacional; (v) uma disciplina própria a criar no âmbito do ensino genérico; e, (vi) uma disciplina de Classes de Conjunto no ensino genérico, alargam o âmbito do possível desenvolvimento do ensino instrumental em grupo.

\section{- Perspectiva das fichas síntese dos sujeitos sobre o ensino instrumental em grupo}

Todos os alunos manifestaram mais interesse pelo ensino instrumental em grupo do que pelo individual e o concerto final (concerto realizado no Conservatório do Vale do Sousa pelos os alunos envolvidos no projeto) desenvolveu um trabalho acrescido e um maior sentido de responsabilidade expresso em expressões como: "era importante"; "se não estudasse o concerto ia correr mal"; "boa reputação"; "para que corresse tudo bem"; "eu não queria enganar-me". O concerto final foi: "bom"; "divertido"; "correu bem"; "muito giro"; "tocámos todos bem" e "foi fantástico"'. Questionados, os alunos sobre as preferências de tocar em conjunto ou individualmente: "as atuações de conjunto, porque são músicas tradicionais"; "em grupo porque é mais divertido"; "as aulas de conjunto porque eram muito engraçadas, cativantes..."; de realçar que um aluno do ensino genérico respondeu: "Eu gostei de tocar das duas maneiras, porque eu gosto de tocar indiferentemente como for" 4 . O ensino instrumental em grupo promoveu e desenvolveu um sentido de trabalho ancorado no espírito de cooperação, entreajuda e livre iniciativa, envolvendo os elementos do grupo, assim como a própria família, verificando-se um estímulo acrescido e uma disponibilidade maior para o processo de ensino aprendizagem.

\section{c) Estabelecimento de articulações curriculares e ações de cooperação concretas com o ensino genérico, com o intuito de contribuir para a construção do projeto educativo da escola}

O funcionamento do ensino vocacional da música e das escolas de música especializadas só é possível se, efetivamente, se operarem determinados pressupostos de entendimento que conduzam a uma efetiva participação dos estabelecimentos de ensino em um projeto de interesse comum. Esta constatação evidente sofreu dificuldades de afirmação e contestação ao longo dos anos, por parte dos diferentes atores, e impossibilitou o desenvolvimento artístico musical durante, sensivelmente, duas décadas e meia (desde a reforma estrutural de 1983, Decreto-Lei no 310, de 1 de julho). As dificuldades de implantação dos regimes de frequência articulado e integrado são o retrato desta evidência, que começa a desvanecer-se nos dias atuais, mas que necessita, ainda, da assunção de outros compromissos e de percursos característicos enraizados nas comunidades locais/regionais para que possibilitem o desenvolvimento de currículos diferenciados. As articulações de colaboração entre as escolas genéricas e especializadas são absolutamente essenciais para a sustentabilidade do regime de frequência articulado

\footnotetext{
3 Opinião emitida pelos alunos na Ficha Síntese Concerto Final (FSCF) realizado no Conservatório do Vale do Sousa em 24 de junho de 2010.

4 Opinião emitida pelos alunos na Ficha Síntese Concerto Final (FSCF) realizado no Conservatório do Vale do Sousa em 24 de junho de 210.
} 
e, quiçá, para o seu desenvolvimento futuro; são, em suma, essenciais para a democratização do acesso a uma aprendizagem musical sustentada na aprendizagem de instrumentos musicais. O diálogo, o acordo, o consenso, a proximidade, a integração e a flexibilidade são aspetos centrais do quadro de entendimento no contexto de uma determinada ecologia éticopolítica. As Escolas de Referência (escolas que reúnem em uma mesma turma, grau e ano, todos os alunos inscritos no ensino da música em regime articulado) criadas ao abrigo de protocolos de colaboração entre a escola especializada e a escola genérica (Portaria no 691/2009, de 25 de junho), tiveram um papel fundamental na abertura das relações de entendimento e de credibilidade junto das escolas envolvidas (pese embora as dificuldades causadas no acesso ao ensino da música pela sua circunscrição). $\mathrm{O}$ ensino vocacional da música em regime articulado saiu beneficiado porque passou a ser encarado em uma perspectiva mais positiva pelos diferentes intervenientes e a oferta da escola básica, ao possibilitar o ensino da música neste regime de frequência, passou a constituir uma maior valência a considerar. No fundo, a oferta do ensino da música em regime articulado, coloca em causa os próprios conceitos de ensino vocacional e de ensino genérico (RIBEIRO, 2008).

A perspectiva do interesse é o denominador comum às duas escolas e a base do desenvolvimento de políticas educativas que considerem a implementação de estratégias eficazes de resposta articulada. Neste contexto, elenca-se um conjunto de medidas apoiadas nos resultados e constatações desta pesquisa e que pretendem contribuir para o melhoramento do regime de frequência:

(i) alargar e melhorar a organização do processo;

(ii) diminuir distâncias entre os estabelecimentos de ensino;

(iii) desenvolver as relações de cooperação e articulação para consolidação e articulação pedagógica;

(iv) planejar conjuntamente atividades de interesse mútuo que constem nos respectivos projetos educativos e planos de atividades de cada escola;

(v) assinar protocolos curriculares que possibilitem a diversificação da oferta educativa;

(vi) reformular o modelo de ensino da música no ensino genérico contemplando duas vertentes: uma facultativa e outra oficial (profissional).

O papel da escola vocacional de música no âmbito destas articulações é fundamental e centra-se nos seguintes aspetos;

(i) dar a conhecer à comunidade o trabalho desenvolvido e sensibilizar para a importância da música na formação dos alunos, constituindo uma porta de opção educacional mantendo uma ligação profunda, eficaz e cooperante com o processo de articulação;

(ii) a elaboração dos horários e das turmas dos alunos deve ser feita conjuntamente com as duas escolas;

(iii) os pais e encarregados de educação devem ser devidamente informados sobre o funcionamento do regime de frequência articulado;

(iv) o ensino vocacional da música deve ser objeto de uma maior divulgação no sentido de esclarecer as vantagens da sua frequência;

(v) realização de intercâmbios pedagógicos e projetos multidisciplinares;

(vi) utilização de diferentes espaços para a lecionação das aulas quer da escola vocacional, quer da escola genérica, quer das disciplinas da música, quer das disciplinas do currículo geral;

(vii) elaboração de atividades devidamente enquadradas e apresentações/audições/concertos/ ações de formação na escola do ensino genérico;

(viii) presença de elementos da escola do ensino artístico especializado da música nos órgãos de gestão da escola genérica: Conselhos Gerais.

As relações de articulação mantidas pelo Conservatório do Vale do Sousa e as escolas do ensino genérico, na atualidade, respondem com satisfação às necessidades dos alunos que frequentam este regime de frequência e modelo de ensino. As razões/vantagens da frequência do ensino da música, neste regime de frequência, tornaram-se claras neste projeto e centram-se em torno de aspectos como a possibilidade de aprender um instrumento musical sem compromisso futuro e de uma formação geral mais completa, independentemente da opção vocacional. O modelo de ensino articulado, neste contexto, não apresenta desvantagens, pese embora o fato da falta de tempo ter sido mencionada, ora para estudar as disciplinas de música, ora para estudar as disciplinas da formação geral. O trabalho empírico desenvolvido veio confirmar o carácter generalista do ensino dito especializado, reforçando a ideia de que se trata apenas de ensino de música tout court, impossibilitando a clara distinção entre os alunos dos dois ramos. As motivações e perspectivas subjacentes aos alunos que participaram do projeto são as mesmas embora os tipos de ensino se situem nos diferentes ramos.

\section{CONCLUSÕES}

De acordo com os dados expostos, sua análise, interpretação e respetivas sínteses conclusivas verifica-se como necessária uma redefinição dos percursos 
formativos capaz de contemplar articulações pedagógicas entre os dois ramos de ensino (vocacional e genérico), que permita novas realidades musicais e uma redefinição também das estratégias de modo a consolidarem práticas pedagógicas e modelos que possibilitem a todos os alunos a aprendizagem de um instrumento, independentemente da opção vocacional futura. Neste sentido, concluiu-se que o ensino da música deve estar ao alcance de todos os cidadãos para que estes usufruam de igualdade de oportunidades no acesso à formação musical e pessoal. A ideia de que este tipo de ensino é dirigido a uma classe socialmente favorecida é uma falsa ideia, pois a realidade atual do caso em estudo mostra-nos, efetivamente, o contrário. Continuar a insistir que a escola vocacional de música necessita de uma determinada população com vocação enquanto talento, aptidão inata e dom natural é negar a realidade deste estudo e o lugar da escola de música, continuar a agir em uma perspectiva ultrapassada e conservadora que não responde às necessidades evidentes do nosso dia a dia e comprometer a assunção do estabelecimento de um verdadeiro ensino da música. A este propósito, Almeida (2009, p.3) refere que a reestruturação do ensino da música, levada a cabo em 2009:

Não é uma revolução silenciosa, porque o seu impacto é bem audível: a democratização e a igualdade no acesso ao ensino da música em Portugal vieram transformar, em pouco mais de uma década, o estado do setor, reduzindo a pó os estereótipos existentes ao longo de sucessivas gerações que insistiam em associar este segmento apenas a estratos sociais mais elevados.

De fato, o ensino da música não pode ser destinado a um público que se crê com comprovadas aptidões artísticas (Decreto-Lei no 344/90, de 2 de novembro) fundadas nas ideias de vocação e talento, porque tais critérios negligenciariam, por um lado:

(i) o importante papel dos fatores ambientais e das vivências no desenvolvimento de determinadas aptidões básicas, não só na música como em qualquer área do conhecimento. Segundo Mota (1997): o principal é o de que o estatuto social e a cultura familiar da criança têm mais peso nos resultados da performance musical, do que as aptidões inatas, os resultados dos testes de entrada nas escolas, ou o ensino formal nos três primeiros anos de instrução. Nesse sentido, conclui-se que um ambiente social mais favorável em casa, envolvendo mais exposição à música de qualidade, revela-se fundamental para o sucesso das crianças na disciplina de música, e que o processo de socialização introduzido pelo ensino nas escolas não é capaz de alterar os dados iniciais do contexto familiar.

Ainda nesta perspectiva e de acordo com Krauss (1974, p. 1-2):
Em geral, os chamados talentosos, são alunos que foram alertados musicalmente na devida altura, mas não pelo ensino musical da escola. [...]. Os ensaios sobre investigação da aprendizagem do talento musical deram resultados que quase sempre são talentosos aqueles seres humanos que tiveram experiências de aprendizagem sistemática em tenra idade, o que faltou a outros.

(ii) por outro lado, esta mesma ideia remeter-nos-ia para a concepção do artista enquanto possuidor de um conjunto de aptidões artísticas especiais e, ele próprio especial; sendo assim, a definição de educação artística vocacional dada pela redação do Decreto-Lei no 344/90, de 2 de novembro (art. $11^{\circ}$ ), implicaria que o ensino artístico vocacional se destinasse a indivíduos especiais, sobredotados, o que é muito questionável que aconteça neste momento.

É natural que a temática em discussão apresente um carácter controverso e não seja pacífica, atendendo à nossa história do ensino da música e à representação simbólica, mas não questionada, associada às instituições de ensino da música no nosso País. Porém, os resultados da pesquisa são claros, pelo que urge estudar outras escolas, aprofundar estes resultados e rever novas formas de ensinar e de aprender para que a música instrumental não seja um privilégio de alguns, mas um direito de todos.

\section{CONSIDERAÇÕES FINAIS}

O trabalho de investigação aqui exposto e os seus resultados manifestam um olhar paradoxal entre dois campos de ação: por um lado, um campo que se movimenta no sentido geral (ensino genérico da música); e por outro lado, um campo especializado que se movimenta em direção a um público determinado (ensino vocacional da música). Ora, estes dois campos legislativamente diferentes têm dificuldades de afirmação e de identidade porque se confrontam um com o outro na medida em que não definem na realidade espaços próprios e propósitos determinados no contexto em estudo. Efetivamente, nesta pesquisa os dois campos comungam de um espaço único sobreposto e dirigem-se a um público idêntico. O ensino vocacional da música movimenta-se no âmbito da generalidade dos indivíduos: mas não assume esta generalidade (apenas um caso ou outro excecional é que procura o ensino da música com fins vocacionais); o ensino genérico da música não permite a possibilidade da opção vocacional (mas os alunos que pretendem seguir a área vocacional da música situam-se no âmbito da generalidade). A resposta ao problema convoca o desfazer do paradoxo em uma linha sustentada na vontade própria de cada um, vontade essa construída com base em uma 
escolaridade obrigatória comum de qualidade que possa garantir qualquer opção vocacional. Nesse sentido o conceito de ensino genérico tem mais a ver com a idade dos alunos, com a iniciação musical, do que com supostos caminhos que possam ser impostos às crianças a priori (VIEIRA, 2014). A música, como qualquer área do saber, deverá ser incluída nessa escolaridade obrigatória e não ser objeto de tratamento desigual, no sentido de excluir a generalidade dos cidadãos colocando a ênfase na vocação inata. De fato, qualquer área do conhecimento necessita da opção vocacional e, por analogia e consequência, da respectiva vocação.

O ensino da música nas escolas especializadas ou ditas vocacionais assenta ainda em consubstanciados preconceitos relacionados com outros estilos e gêneros musicais. A perspectiva erudita não tem permitido propostas pedagógicas e abordagens inovadoras e diferenciadas. Este estudo comprova que a escola de música deverá acima de tudo ser plural, deve responder à diversificação da população e permitir o desenvolvimento da sua comunidade em uma perspectiva integrada com o ensino genérico, articulando com as escolas básicas e secundárias de igual para igual em uma mesma linha hierárquica. A escola de música necessita assim de um espírito renovado, forte e consciente para reformular o processo e fortalecer o produto com base em uma filosofia de ensino: tudo para todos.

\section{REFERÊNCIAS}

ALMEIDA, Sérgio. Uma revolução bem audível. Jornal de Notícias, Porto, 29 nov. 2009. Sociedade, p. 3.

FERNANDES, Domingos; Ó, Jorge; FERREIRA, Mário. Estudo de avaliação do ensino artístico. Lisboa: Direcção Geral de Formação Vocacional do Ministério da Educação e Faculdade de Psicologia e de Ciências da Educação da Universidade de Lisboa, 2007. Disponível em: http://hdl. handle.net/10451/5501. Acesso em: 17 maio 2015.

FOLHADELA, Paula; VASCONCELOS, António Ângelo; PALMA, Eduardo. Ensino Especializado da Música Reflexões de Escolas e de Professores. Lisboa: ME, Departamento do Ensino Secundário, 1998.

KRAUSS, Egon. O ensino da música como matéria obrigatória nas escolas primárias. Boletim Informativo da Associação Portuguesa de Educação Musical, Lisboa, n. 5, p. 1-12, 1974.

MINISTÉRIO DA EDUCAÇÃO. Reforma do ensino secundário: documento orientador da reforma do ensino artístico especializado - versão para discussão pública. Lisboa: Edição do Autor, 2003.

MOTA, Graça. Determinants of children's musical development in the early years of general classroom music instruction. 1997. 142f. Tese (Doutorado em Psicologia da Música) - Faculdade de Ciências Naturais e Faculdade de Humanidades e Ciências Sociais, Keele University, Keele, 1997.

PALHEIROS, Graça Boal. Educação Musical no Ensino Preparatório - Uma Avaliação do Currículo. Lisboa: APEM, 1993.

PORTUGAL. Decreto-Lei no 310/83, de 1을 de julho Insere o ensino artístico nos moldes gerais de ensino em vigor através da reconversão dos conservatórios de música em escolas básicas e secundárias, criando as respetivas escolas superiores de música inseridas na estrutura de ensino superior politécnico.

PORTUGAL. Decreto-Lei no 344/90, de 2 de novembro Estabelece as bases da educação artística no âmbito pré-escolar, escolar e extraescolar.

PORTUGAL. Portaria no 691/2009, de 25 de junho - Cria os cursos básicos de dança, de música e de canto gregoriano e aprova os respetivos planos de estudo.

RIBEIRO, António Pacheco. O Ensino da Música em Regime Articulado no Conservatório do Vale do Sousa: Função Vocacional ou Genérica? 2008. 150f. Dissertação (Mestrado em Estudos da Criança - Educação Musical) Instituto de Estudos da Criança, Universidade do Minho, Braga, 2008.

\section{RIBEIRO, António Pacheco. O Ensino da Música em} Regime Articulado. Projeto de Investigação-Ação no Conservatório do Vale do Sousa. 2013. 214f. Tese (Doutorado em Estudos da Criança) - Instituto de Educação, Universidade do Minho, Braga, 2013.

RIBEIRO, António Pacheco; VIEIRA, Maria Helena. The subsystem of specialized music education in Portugal since 1983: The process of integration into the general education system. International Journal of Music Education, Londres, v. 34, n. 3, p. 311-323, 2016a. Disponível em: https://doi.org/10.1177/0255761415619424. Acesso em: 10 jan. 2016.

RIBEIRO, António Pacheco; VIEIRA, Maria Helena. A articulação entre o ensino especializado da música e o sistema geral de ensino em Portugal: impacto actual da reestruturação de 2009. Opus, [S. l.], v. 22, n. 1, p. 237-254, jun. 2016 b. Disponível em: http://dx.doi.org/10.20504/opus2016a2210. Acesso em: 20 fev. 2017.

SILVA, Augusto Santos. A educação artística e a promoção das artes, na perspectiva das políticas públicas: Relatório do grupo de contacto entre os Ministérios da Educação e da Cultura. Lisboa: Ministério da Educação, 2000.

VASCONCELOS, António Ângelo. Políticas no ensino da música em Portugal nas últimas duas décadas do século XX: contributos para uma análise crítica. Revista de Educação Musical, Braga, n. 115, p. 14-28, abr. 2003. 
VIEIRA, Maria Helena. The portuguese system of music education: teacher training challenges. In: LOCAL AND GLOBAL PERSPECTIVES ON CHANGE IN TEACHER EDUCATION. INTERNATIONAL YEARBOOK ON TEACHER EDUCATION. WORLDASSEMBLY OF THE INTERNATIONAL COUNCIL ON EDUCATION FOR TEACHING, 53, 2008, Braga. Proceedings [...]. Braga: Universidade do Minho, 2008. p. 639-646.

VIEIRA, Maria Helena.. O desenvolvimento da vocação musical em Portugal. O currículo como factor de instabilidade e desmotivação. In: CONGRESSO INTERNATIONAL GALEGO-PORTUGUÊS DE PSICOPEDAGOGIA, X, 2009, Braga. Anais [...]. Braga: Universidade do Minho, 2009. p. 530-537.

VIEIRA, Maria Helena.. Passado e Presente do Ensino Especializado da Música em Portugal: E se Explicássemos Bem o que Significa "Especializado"? In: ENCONTRO DO ENSINO ARTÍSTICO ESPECIALIZADO DA MÚSICA DO VALE DO SOUSA, I, 2014, Lousada. Atas [...]. Lousada: Conservatório do Vale do Sousa, 2014. p.60-74.

Recebido em: 9/8/2017.

Aprovado em: 6/11/2018.

Publicado em: 30/4/2019.

Endereço para correspondência:

António José Pacheco Ribeiro

Universidade do Minho - Instituto de Educação

Campus de Gualtar

4710-057, Braga, Portugal

\section{Autores:}

ANTÓNIO JosÉ PACHECO RIBEIRO

Professor Convidado Equiparado a Professor Auxiliar. Universidade do

Minho - Instituto de Educação/CIEC (Centro de Investigação em Estudos da

Criança), Portugal.

Orcid: http://orcid.org/0000-0003-3413-8473

E-mail: antoniopacheco@ie.uminho.pt

Maria Helena Gonchalves Leal Vieira

Professora Auxiliar. Universidade do Minho - Instituto de Educação/CIEC

(Centro de Investigação em Estudos da Criança), Portugal.

Orcid: http://orcid.org/0000-0003-1346-1925

E-mail: m.helenavieira@ie.uminho.pt 